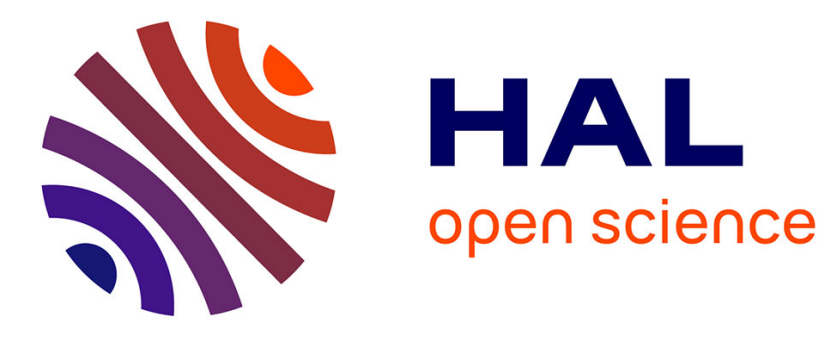

\title{
Preventable breast cancer is postmenopausal
}

Kari Hemminki, Asta Försti, Jan Sundquist, Seyed Mohsen Mousavi

\section{To cite this version:}

Kari Hemminki, Asta Försti, Jan Sundquist, Seyed Mohsen Mousavi. Preventable breast cancer is postmenopausal. Breast Cancer Research and Treatment, 2010, 125 (1), pp.163-167. 10.1007/s10549010-0926-8 . hal-00555003

\section{HAL Id: hal-00555003 https://hal.science/hal-00555003}

Submitted on 12 Jan 2011

HAL is a multi-disciplinary open access archive for the deposit and dissemination of scientific research documents, whether they are published or not. The documents may come from teaching and research institutions in France or abroad, or from public or private research centers.
L'archive ouverte pluridisciplinaire HAL, est destinée au dépôt et à la diffusion de documents scientifiques de niveau recherche, publiés ou non, émanant des établissements d'enseignement et de recherche français ou étrangers, des laboratoires publics ou privés. 


\section{PREVENTABLE BREAST CANCER IS POSTMENOPAUSAL}

Kari Hemminki ${ }^{1,2,3}$, Asta Försti ${ }^{1,2}$, Jan Sundquist ${ }^{2,4}$ and Seyed Mohsen Mousavi ${ }^{1,5}$

${ }^{1}$ Division of Molecular Genetic Epidemiology, German Cancer Research Centre (DKFZ), 69120 Heidelberg, Germany; ${ }^{2}$ Center for Primary Care Research, Lund University, Malmö, Sweden; ${ }^{3}$ Center for Family and Community Medicine, Karolinska Institute, 14183 Huddinge, Sweden; ${ }^{4}$ Stanford Prevention Research Center, Stanford University School of Medicine, California, USA

${ }^{5}$ Cancer Research Center of Cancer Institute, Tehran University of Medical Sciences, Tehran, Iran

Correspondence to Kari Hemminki <k.hemminki@dkfz.de>

Running title: Age-incidence.

Word count: 239 abstract, 1687 text.

Key words: ethnic differences, age-incidence, risk factors, environmental effect, incidence change. 


\begin{abstract}
Breast cancer incidence has markedly increased in Western countries for reasons that are not entirely understood. We characterized periodic and age-specific incidence trends of breast cancer in immigrants who migrated from low-incidence areas to Sweden. The incidence in immigrants was compared to that in native Swedes and standardized incidence ratios (SIRs) were calculated, based on the Swedish Family-Cancer Database. Age-specific incidence data for low-and high-incidence populations were obtained from Cancer Incidence in Five Continents IX and NORDCAN. For immigrants from the seven lowest countries/regions 535 breast cancers were identified; the SIRs ranging from 0.45 for Turkish to 0.70 for Greek women. The SIR increased somewhat with the length of stay in Sweden, from 0.55 for stay between 0 and 10 years to 0.59 for a stay of 20+ years. The age-specific incidence curves for these immigrants were superimposable upon the earliest Swedish (year 1960) or Danish (1943) rates. These rates differed from the current Swedish rates by a much lower postmenopausal component. Large incidence differences were also observed between white Californians and immigrants from China and Korea. Our results show that the main difference between high and low incidence areas is in postmenopausal cancer which has increased preferentially during the past century. Immigrants from low-risk areas to Sweden show age-specific incidence patterns of Swedes half a century ago. These differences offer opportunities for the identification of factors underlying breast cancer etiology and tools for prevention.
\end{abstract}




\section{INTRODUCTION}

The incidence of female breast cancer is increasing in developing Asian and African countries but the rates are no more than $25 \%$ of those in North America and Western Europe. There is also a major difference in age-specific incidence rates between low-risk and high-risk regions, which can be observed in ad hoc studies and in Cancer Incidence in Five Continents data $[15,18,22,26,28]$. In developing countries maximal incidence rates occur in the age band 45 to 54 years, while in developed countries maximal incidence rates are reached at older ages [15, 23, 27, 28]. Data from Cancer Incidence in Five Continents IX are shown in Fig. 1 for China, India, Algeria, Sweden and USA, all countries covered by well-functioning regional or national cancer registries (note the logarithmic y-axis). The incidence differences are small until age 30 years, when the low-incidence rates diverge and reach a maximum at age 50 years. The postmenopausal rates are over 350/100,000 for USA and Sweden while those for developing countries remain within the interval 50100/100,000. Mammography has shifted the age maxima towards younger ages even in high-incidence countries, including Sweden, with a nation-wide mammographic screening program, which was implemented between years 1986 and 1997 [11, 12, 24].

A careful analysis of the time-dependent and ethnic variation in age-specific incidence patterns and, particularly, after immigration to a new environment, may advance understanding on breast cancer etiology and prevention. We analyzed age-specific incidence relationships for breast cancer in female immigrants to Sweden and compared the results to the historic data from Sweden and Denmark. The study is based on the nation-wide Family-Cancer Database with 11.8 million individuals, among whom some $15 \%$ are foreign born [7].

\section{SUBJECTS AND METHODS}

The Swedish Family-Cancer Database was first assembled from the national databases in 1996 and since then it has been periodically updated [10]. The Database contains those born in Sweden since 1932 with their biological parents and additionally data on immigrants are included. This Database is the largest in the world on familial cancer and its updated version (2008, VIII) which has been supplied with longitudinal demographic and socio-economic data from each national census of 1960, 1970, 1980 and 1990 has been used for the present study [7]. The parental information was classified according to the country of birth. 
The incidence in immigrants was compared to that in native Swedes and standardized incidence ratios (SIRs) were calculated, as previously [9]. The expected numbers were calculated for 5-year age groups, sex, time periods (10-year bands from 1958 to 2006) age at first child birth $(<20,20-24,25-29,30+)$ and parity $(0,1,2+)$ in the native Swedish reference population. Based on SIRs, immigrants with seven lowest significant risks were considered for age-specific analyses (Turkey SIR 0.45, Chile 0.54, Southeast Asia 0.57, Indian subcontinent 0.61, Africa, excluding North Africa, 0.64, East Asia 0.71 and Greece 0.70). Age specific incidence data were calculated for cancer diagnosed from 1990 through 2006. The Cancer Incidence in Five Continents IX data, covering year 1998-2002, were available at the IARC web site CancerMondial [15]. The NORDCAN data for Sweden and Denmark were also accessed through the IARC web site.

\section{RESULTS}

The age-specific incidence data among immigrants from seven countries/regions with the lowest breast cancer risk are shown in Fig. 2, divided in three groups based on the length of stay in Sweden (0-10, 11-19 and 20+). The curves were reasonably similar up to age 50-59 years but at a higher age the incidence increased steeply for women who had stayed 20+ years in Sweden. The SIR was 0.58 (N=535, 95\%CI 0.530.63 ) for all selected immigrants in years 1990-2006 compared to native Swedes (SIR =1.00). By the length of stay the SIRs were 0.55 for 0-10 years, 0.58 for $11-19$ years and 0.59 for $20+$ years.

Cancer registration started relatively early in the Nordic countries and we accessed the data for the earliest age-specific data for breast cancer through NORDCAN. The data for Denmark from year 1943 and Sweden from year 1960 are shown together with the data from the seven Swedish immigrant groups with the lowest breast cancer incidence (Fig. 3). The curves are practically superimposable.

The main Asian immigration to USA started after 1965 when immigration laws were changed. Over 2.4 million Chinese and 1 million Koreans have immigrated mainly to California [20]. The incidence rates for breast cancer are lowest for these ethnic groups among the main ethnic groups in California [4]. The Los Angeles and San Francisco cancer registries report data by ethnicity as shown in Fig. 4 for years 1998-2002, based on Cancer Incidence in Five Continents [15]. The age-specific incidence curves for non-Hispanic white populations are superimposable (and only Los Angeles curve is shown), leveling off at a rate of 500/100,000, 
compared to a rate at 200/100,000 or less for the Asian immigrants (logarithmic scale). The age-standardized incidence for Los Angeles whites was 110.0/100,000 for 0-85+ years, 34.4/100,000 for 0-49 years and 412.4/100,000 for 50-85+ years [15]; incidence difference between these age groups was thus 12.0-fold, typical of the high incidence countries (Sweden 10.9-fold). For Los Angeles Chinese, the incidence rates were 52.1, 26.6 and 153.9/100,000, respectively, giving a 5.8-fold difference between age groups below 50 years and older. Among Los Angeles Koreans, the difference was 6.2-fold. These are typical of the incidence differences for women in developing countries (Shanghai 6.2-fold, Chennai 6.7-fold and Algeria 4.9-fold) [15].

\section{DISCUSSION}

Many authors have previously presented evidence that premenopausal and postmenopausal breast cancers are different diseases $[3,16]$. The novelty of the present work is that we can show, based on the current and historic Nordic data, that the main increase in breast cancer burden accumulated over the past half century has been in postmenopausal women. As a consequence, the incidence difference between postmenopausal (age 50+ years) and premenopausal breast cancer increased from about 6 in developing countries to 10-12 in high incidence countries. Remarkably, the age-specific incidence curves of the Swedish immigrants from low-risk areas resemble the Swedish and Danish rates half a century ago. Such differences can also be observed for Asian immigrants to California compared to the white population. In Swedish immigrants, the rates for postmenopausal breast cancer increased somewhat by the length of stay in Sweden (SIR 0.55 0-10 years and SIR 0.59 20+ years). Larger changes have been observed for Chinese immigrants in Californian whose rates more than doubled after 22 years of stay compared to the newly arrived immigrants and then reached 2/3 of the rates for those born in California [31]. That study also showed that Chinese who immigrated to California at age over 40 years had essentially the risk of the newly arrived, implying that immigration does not change breast cancer risk after age 40 years. We have reviewed age-specific incidence data on all other populations for which data are available by ethnicity in Cancer Incidence in Five Continents IX, including Hawaii, Singapore and Israel. For Hawaii, Chinese and Filipino the rates leveled off at age 50 yeas similar to Chinese in California. The same patterns were observed for Non-Jews in Israel. The ethnic groups in Singapore had more complex patterns.

The causes of the vast increase in breast cancer incidence in the developed counties are not known precisely but decreased physical inactivity, weight gain, delayed childbirth and earlier menarche have been implicated 
[2]. The Swedish immigrant data were adjusted for parity and age at first childbirth but factors such as lactation and attendance for mammographic screening could not be controlled for. Limited historical data from developing countries suggest that lactation has often been continued for two years [6]. Long lactation times have also been recorded among immigrants to Sweden: 6-month breastfeeding rates were not different from Swedes but 12-month rates were lower for Swedes (18\%) than for e.g., Africans (44\%) and Middle Easterners (36\%) [29]. The participation of non-Nordic immigrants to the national mammographic screening program has been somewhat lower (about 80\%) compared to Swedes (90\%) [19]. However, the difference is not large and, at least transiently, mammography increases cancer incidence $[13,21,30]$.

The present results outline opportunities for targeted research and prevention strategies. Firstly, the demography of postmenopausal and premenopausal breast cancer differs and the large international variation in incidence is mainly contributed by postmenopausal breast cancer. Environmental (lifestyle) factors have probably contributed to the increase in postmenopausal breast cancers and these, such as physical activity avoidance of overweight, could be targets of prevention [1,14]. This applies also to developing countries where breast cancer incidence is increasing faster than in developed countries [25]. Secondly, the Swedish data show that the length of stay in Sweden had a small effect on breast cancer risk, suggesting that the majority of the risk is programmed early in life, probably before adulthood. Although the Californian data showed larger changes by length of stay, they were also consistent with an early critical period [31]. According to the previous Swedish immigrant studies such early life critical periods appear to apply for many types of cancer, in addition to breast cancer [8,9]. Physical activity in 50 to 74 year old women influences favorably circulating sex hormone patterns but the effects are small and probably call for life-long physical activity [5]. Thirdly, the Swedish results showed that the immigrants from low risk countries are a model for study of risk factors that caused the large surge in postmenopausal breast cancer in the course of a half century in high incidence countries. Logistically, study of immigrants and locals would be very much simpler and subject to fewer biases than trying to compare populations from geographically distinct low and high incidence areas. Finally, even though the incidence of breast cancer has increased during the past half century, mortality has been relatively stable and decreased in many developed countries during past 10 to 20 years $[17,21,25]$. However, the experience from cancer epidemiology tells, without exception, that a decrease in incidence also reduces mortality from that cancer. Thus efforts to prevent postmenopausal breast cancer are likely to be rewarding not only in terms of reducing mortality but avoiding the traumatizing effects of cancer diagnosis. 


\section{ACKNOWLEDGMENTS}

Supported by the Swedish Council for Working Life and Social Research, the Swedish Cancer Society and Deutsche Krebshilfe. The used database was created by linking registers maintained at Statistics Sweden and the Swedish Cancer Registry.

\section{AUTHOR CONTRIBUTIONS}

KH conceived the study, supervised the analysis and wrote the manuscript.

AF critically reviewed the result.

JS provided the data for analysis.

MSS carried out the analyses.

All authors reviewed the final manuscript.

\section{CONFLICT OF INTEREST}

None

\section{REFERENCES}

[1] Bernstein L (2008) Identifying population-based approaches to lower breast cancer risk. Oncogene 27 Suppl 2: S3-8

[2] Boyle P, Levin B (eds) (2008) World Cancer Report 2008. IARC, Lyon.

[3] de Waard F (1979) Premenopausal and postmenopausal breast cancer: one disease or two? J Natl Cancer Inst 63: 549-52

[4] Deapen D, Liu L, Perkins C, Bernstein L, Ross RK (2002) Rapidly rising breast cancer incidence rates among Asian-American women. Int J Cancer 99: 747-50

[5] Friedenreich CM, Woolcott CG, McTiernan A, Ballard-Barbash R, Brant RF, Stanczyk FZ, Terry T, Boyd NF, Yaffe MJ, Irwin ML, Jones CA, Yasui Y, Campbell KL, McNeely ML, Karvinen KH, Wang Q, Courneya KS (2010) Alberta Physical Activity and Breast Cancer Prevention Trial: Sex Hormone Changes in a Year-Long Exercise Intervention Among Postmenopausal Women. J Clin Oncol in press

[6] Grummer-Strawn L (1996) The effect of changes population characteristics on breastfeeding trends in fifteen developing countries Int J Epidemiol 25: 94-102

[7] Hemminki K, Ji J, Brandt A, Mousavi SM, Sundquist J (2010) The Swedish Family-Cancer Database 2009: Prospects for histology-specific and immigrant studies. Int J Cancer 126: 2259-67

[8] Hemminki K, Li X (2002) Cancer risks in second-generation immigrants to Sweden. Int J Cancer 99: 229-37

[9] Hemminki K, Li X, Czene K (2002) Cancer risks in first generation immigrants to Sweden. Int J Cancer 99: 218-28

[10] Hemminki K, Li X, Plna K, Granström C, Vaittinen P (2001) The nation-wide Swedish FamilyCancer Database: updated structure and familial rates. Acta Oncol 40: 772-7

[11] Hemminki K, Lorenzo Bermejo J (2005) Effects of screening for breast cancer on its ageincidence relationships and familial risk. Int J Cancer 117: 145-9

[12] Hemminki K, Rawal R, Lorenzo Bermejo J (2004) Mammographic screening is dramatically changing age-incidence data for breast cancer. J Clin Oncol 22: 4652-3

[13] IARC (2002) Breast cancer screening. IARC Press, Lyon. 
[14] IARC (2002) Weight Control and Physical Activity. IARC, Lyon.

[15] IARC (2007) Cancer Incidence in Five Continents, Vol. IX. . IARC, Lyon.

[16] Jatoi I, Anderson WF, Rosenberg PS (2008) Qualitative age-interactions in breast cancer: a tale of two diseases? Am J Clin Oncol 31: 504-6

[17] Jatoi I, Miller A (2003) Why is breast-cancer mortality declining? Lancet Oncol 4: 251-4

[18] Kwong A, Cheung P, Chan S, Lau S (2008) Breast cancer in Chinese women younger than age 40: are they different from their older counterparts? World J Surg 32: 2554-61

[19] Lagerlund M, Maxwell AE, Bastani R, Thurfjell E, Ekbom A, Lambe M (2002)

Sociodemographic predictors of non-attendance at invitational mammography screening--a populationbased register study (Sweden). Cancer Causes Control 13: 73-82

[20] McCracken M, Olsen M, Chen MS, Jr., Jemal A, Thun M, Cokkinides V, Deapen D, Ward E (2007) Cancer incidence, mortality, and associated risk factors among Asian Americans of Chinese, Filipino, Vietnamese, Korean, and Japanese ethnicities. CA Cancer J Clin 57: 190-205

[21] Miller A (2010) Conundrums in screening for cancer. Int J Cancer 126: 1039-46

[22] Mousavi SM, Montazeri A, Mohagheghi MA, Jarrahi AM, Harirchi I, Najafi M, Ebrahimi M

(2007) Breast cancer in Iran: an epidemiological review. Breast J 13: 383-91

[23] Mousavi SM, Zheng T, Dastgiri S, Miller AB (2009) Age distribution of breast cancer in the middle East, implications for screening. Breast J 15: 677-9

[24] Olsson S, Andersson I, Karlberg I, Bjurstam N, Frodis E, Hakansson S (2000) Implementation of service screening with mammography in Sweden: from pilot study to nationwide programme. J Med Screen 7: 14-8

[25] Parkin DM, Bray FI, Devesa SS (2001) Cancer burden in the year 2000. The global picture. Eur J Cancer 37 Suppl 8: S4-66

[26] Parkin DM, Sitas F, Chirenje M, Stein L, Abratt R, Wabinga H (2008) Part I: Cancer in Indigenous Africans--burden, distribution, and trends. Lancet Oncol 9: 683-92

[27] Smigal C, Jemal A, Ward E, Cokkinides V, Smith R, Howe HL, Thun M (2006) Trends in breast cancer by race and ethnicity: update 2006. CA Cancer J Clin 56: 168-83

[28] Tavassoli F, Devilee P (eds) (2003) Tumours of the breast and female genital organs. IARC Press, Lyon.

[29] Wallby T, Hjern A (2009) Region of birth, income and breastfeeding in a Swedish county. Acta Paediatr 98: 1799-804

[30] Zahl PH, Maehlen J, Welch HG (2008) The natural history of invasive breast cancers detected by screening mammography. Arch Intern Med 168: 2311-6

[31] Ziegler RG, Hoover RN, Pike MC, Hildesheim A, Nomura AM, West DW, Wu-Williams AH, Kolonel LN, Horn-Ross PL, Rosenthal JF, Hyer MB (1993) Migration patterns and breast cancer risk in Asian-American women. J Natl Cancer Inst 85: 1819-27 
Figure 1. Age specific incidence rate for female breast cancer in selected countries or regions based on Cancer Incidence in Five Continents IX in 1998 to2002 (logarithmic scale).

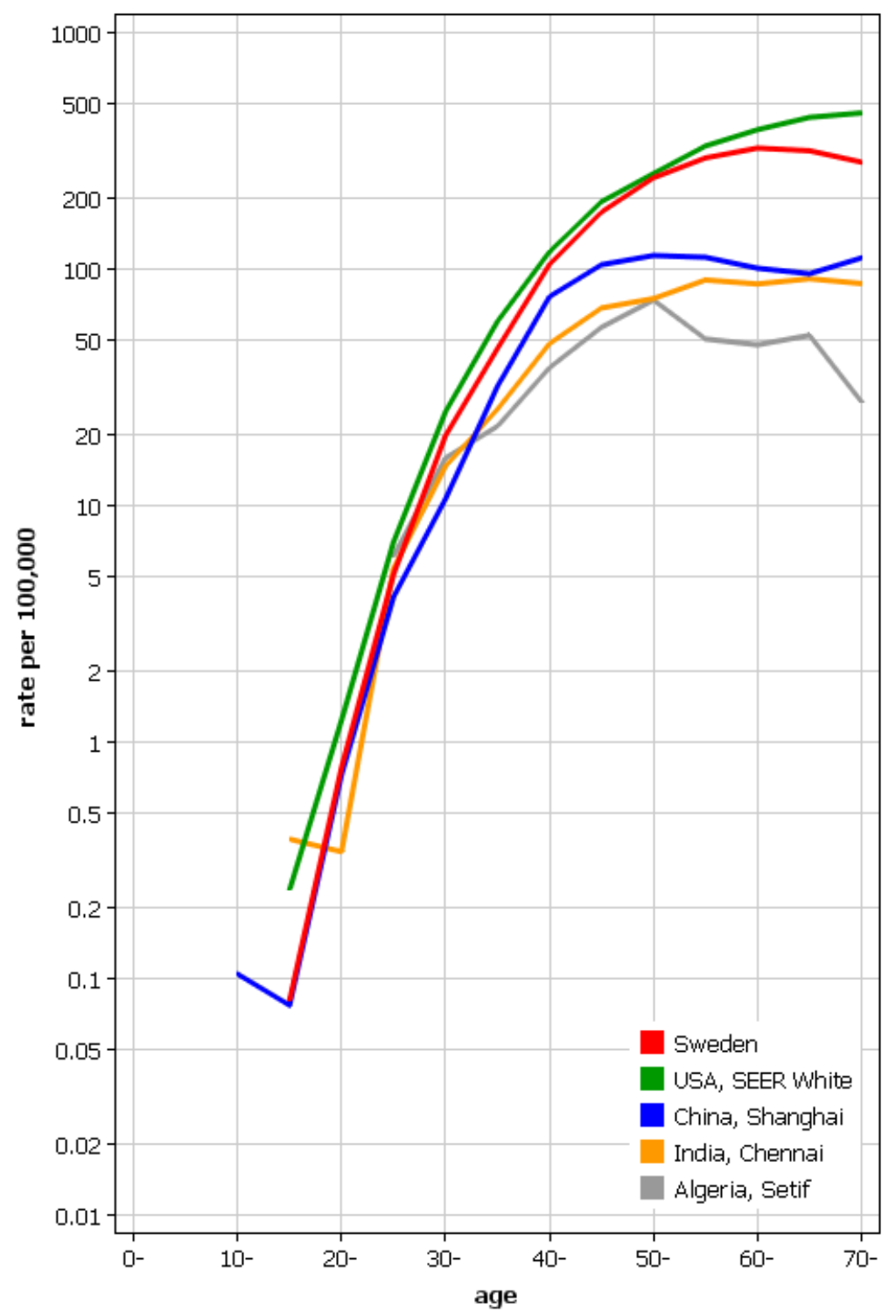

* Curado. M. P., Edwards, B., Shin. H.R., Storm. H., Ferlay. J., Heanue. M. and Boyle. P., eds (2007) Cancer Incidence in Five Continents, Vol. IX, IARC Scientific Publications No. 160, Lyon, IARC. 
Figure 2. Age specific incidence rates of breast cancer among Swedes and immigrants with the lowest rates according to the length of stay in Sweden from 1990 to 2006. Case numbers are shown for each age group.

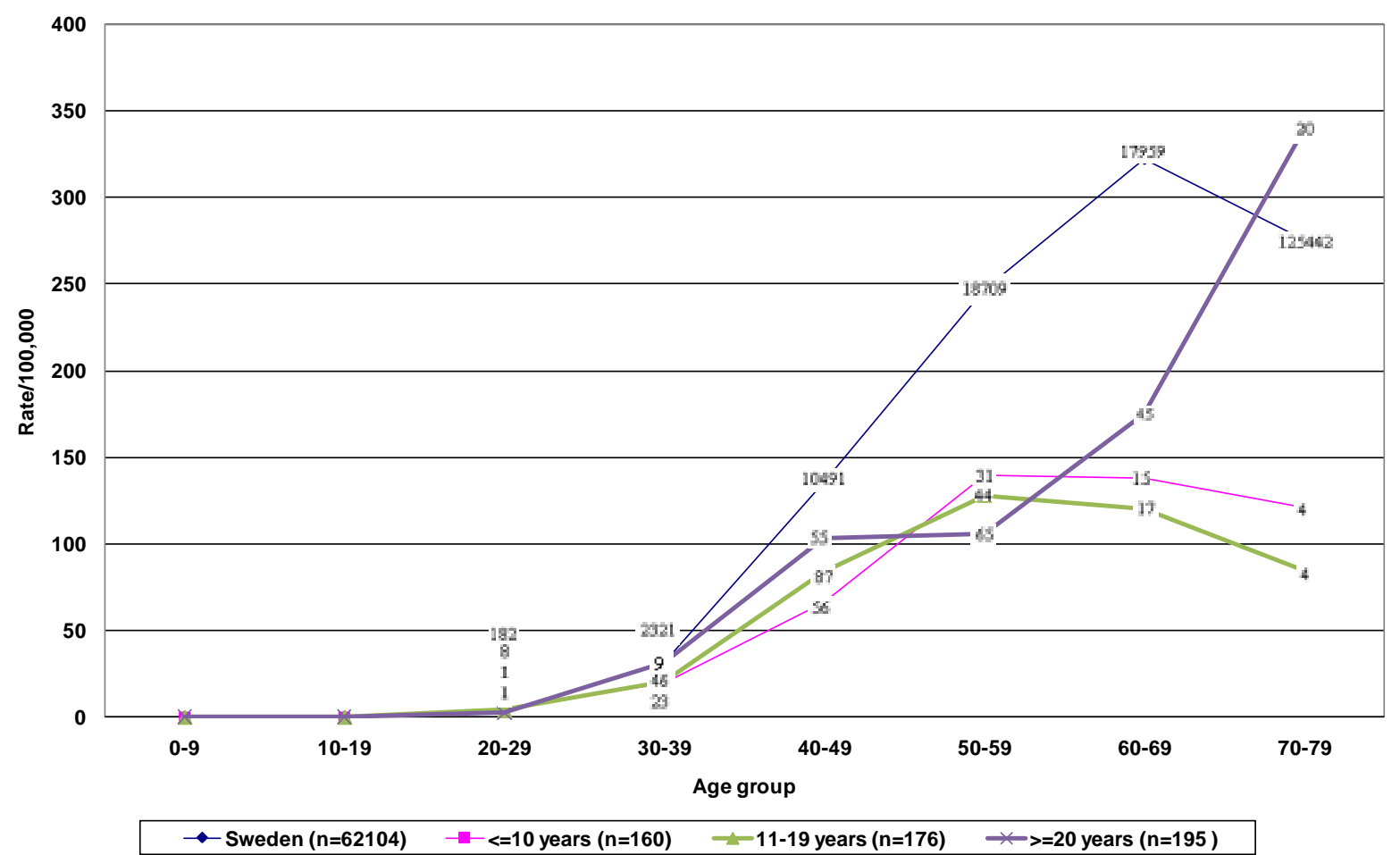

* The lowest breast cancer incidence countries: Turkish, Greek, Southeastern Asian, East Asian, Chilean, Indian, North African and other African immigrants 
Figure 3. Age specific incidence rates of breast cancer among Swedes in year 1960, Danes in year 1943 and immigrants with the lowest rates from 1990 to 2006.

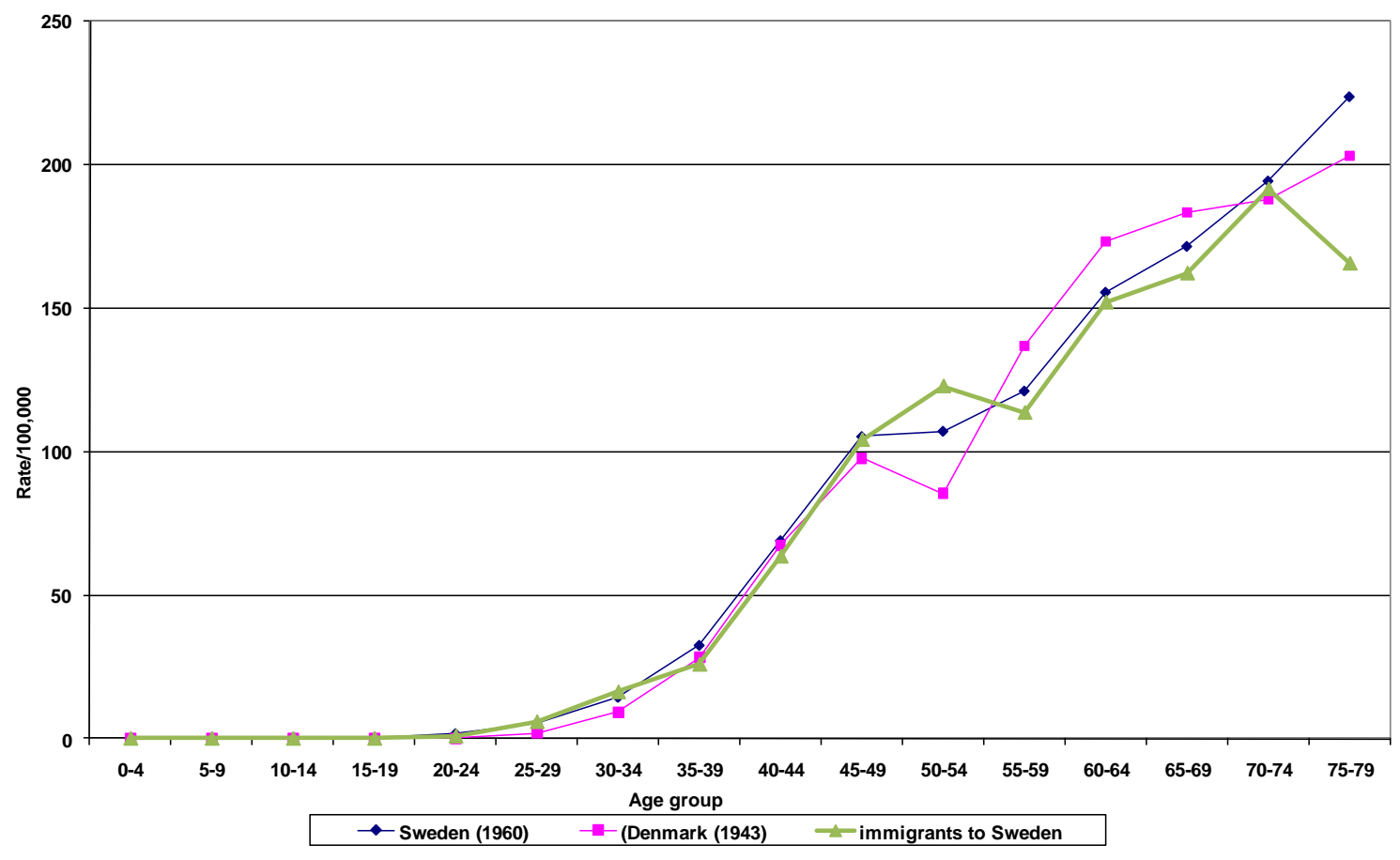

* The lowest breast cancer incidence countries: Turkish, Greek, Southeastern Asian, East Asian, Chilean, Indian, North African and other African immigrants 
Figure 4. Age specific incidence rates of breast cancer among white Californians and Asian immigrants in 1998 to 2002 based on Cancer Incidence in Five Continents IX (logarithmic scale).

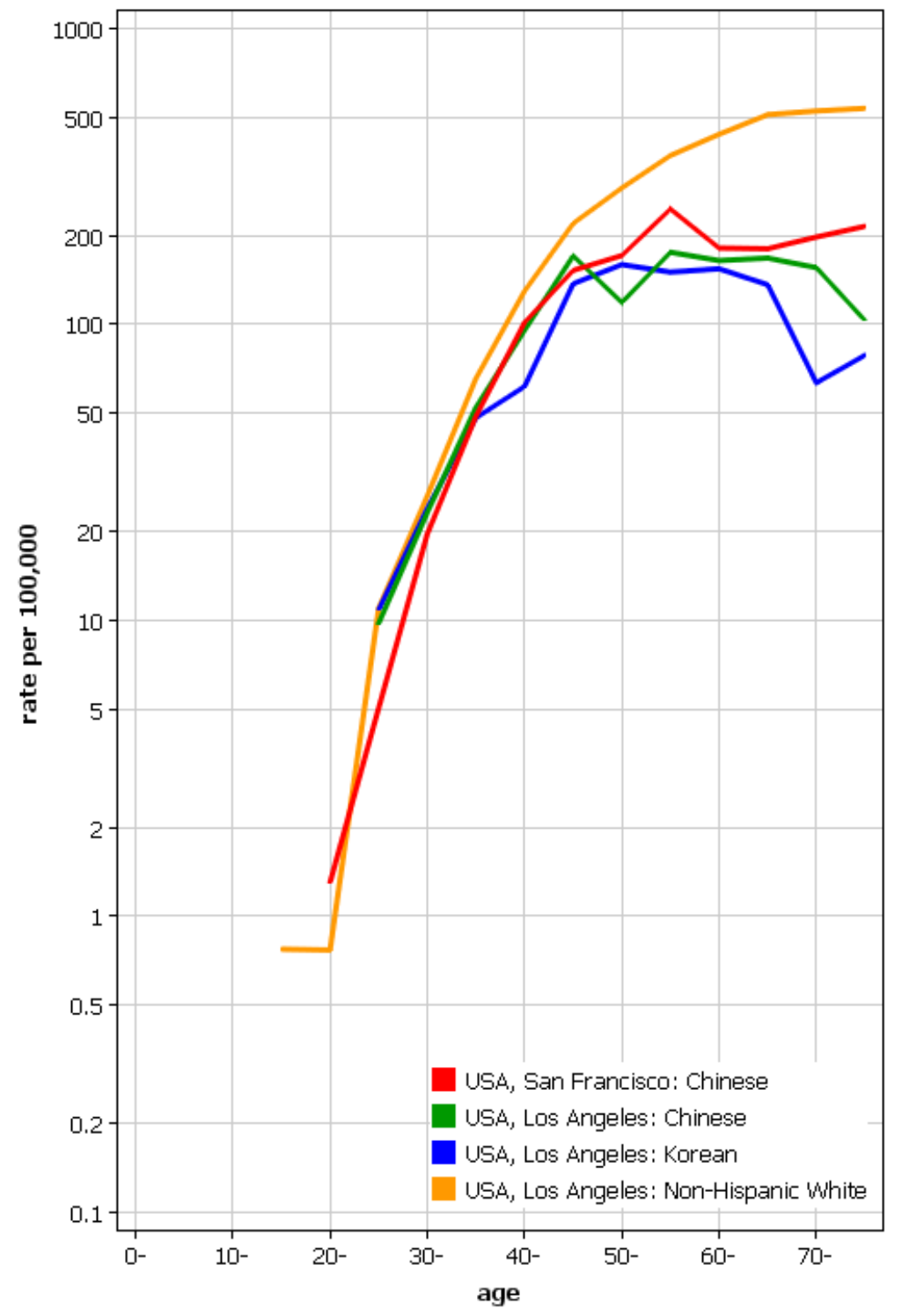

* Curado. M. P., Edwards, B., Shin. H.R., Storm. H., Ferlay. J., Heanue. M. and Boyle. P., eds (2007) Cancer Incidence in Five Continents 